\title{
Antigas Salinas Urbanas e sua Oportunidade para promover Cidades Verdes: O Caso do Parque Estadual do rio Cocó em Fortaleza, Ceará, Brasil
}

\section{Antiguas Salinas Urbanas y su Oportunidad de promover Ciudades Verdes: El Caso del Coco Park en Fortaleza, Ceará, Brasil}

\section{Antique Urban Salt Extraction and their Opportunity to promote Green Cities: The Cocó Park case in Fortaleza, Ceará, Brazil}

Maria do Carmo, Universidad de Brasilia, Universidad Politécnica de Madrid

DOI: $10.20868 /$ ciur.2020.129.4407

\section{PALAVRAS CHAVES:}

Salinas no Brasil / Mangues costeiros / Parque Urbano / Produção de sal no Brasil

\section{DESCRIPTORES:}

Salinas en Brasil / Manglares costeros / Parque Urbano / Producción de sal en Brasil

\section{KEY WORDS:}

Salt extraction in Brazil / Coastal mangroves / Urban Park / Salt Production in Brazil

\section{RESUMO:}

Esse ensaio contextualiza a produção de sal marinho no Brasil e sua localização no período colonial, próximo aos povoados da costa nordestina para investigar a inserção das antigas salinas nas cidades. As salinas artesanais foram transformadas em áreas residenciais, mas dada as condições ambientais de algumas áreas, ainda, existe a oportunidade de integrá-las na condição de infraestrutura urbana verde resgatando, também, sua memória cultural. Assim, se faz uma evolução das áreas ocupadas por salinas e dos métodos de produção, quando se situa às condições mais propícias a produção do sal, bem como, seus conflitos com a proteção dos ecossistemas de manguezais das planícies flúviomarítimas. Se discute a capacidade de regeneração desses ecossistemas em áreas de salinas desativadas e sua oportunidade de instalação de parques urbanos em cidades desprovidas de verde. O caso de estudo ocorre na área das antigas Salinas Diogo, que hoje é o Parque do rio Cocó na cidade de Fortaleza. Como resultado se destaca a integração das áreas de salinas à cidade com grande ganho de qualidade de vida urbana, mas que, por outro lado, as salinas não comparecem na imagem coletiva urbana o que remete a um estudo de 
proteção da memória da paisagem cultural.

\section{RESUMEN:}

Este ensayo contextualiza la producción de sal marina en Brasil y su ubicación en el período colonial, cerca de las aldeas de la costa noreste para investigar la inserción de antiguas salinas en las ciudades. Las salinas artesanales se transformaron en áreas residenciales, pero dadas las condiciones ambientales de algunas áreas, todavía existe la oportunidad de integrarlas en la condición de infraestructura urbana verde, también rescatando su memoria cultural. Las áreas ocupadas por solución salina y los métodos de producción evolucionan cuando se crean las condiciones más favorables para la producción de sal, así como sus conflictos con la protección de los ecosistemas de manglar de las llanuras marítimas fluviales. Se discute la capacidad regenerativa de estos ecosistemas en áreas de salinas desactivadas y su oportunidad de instalar parques urbanos. El estudio de caso ocurre en el área del antiguo Salinas Diogo, que hoy es el Parque del Río Cocó. Como resultado, se destaca la integración de las áreas salinas en la ciudad, con una gran ganancia en la calidad de vida urbana, pero las soluciones salinas no aparecen en la imagen colectiva urbana, lo que lleva a un estudio de protección de la memoria del paisaje cultural.

\section{ABSTRACT:}

This essay contextualizes the production of sea salt in Brazil and its location in the colonial period, close to the northeastern coast villages to investigate the insertion of old salt flats in cities. The artisanal salt extraction were transformed into residential areas, but given the environmental conditions of some areas, there is still the opportunity to integrate them in the city, also rescuing their cultural memory. Occupied areas and production methods are evolved when the conditions most favorable to salt production, as well as their conflicts with the protection of mangrove ecosystems of the river-maritime plains are made. The regenerative capacity of these ecosystems in areas of deactivated salt production and their opportunity to install urban parks in cities are discussed. The case study occurs in the area of the former Salinas Diogo, which today is the Cocó River Park. As a result, the integration of saline areas into the city stands out, with a great gain in urban quality of life, but, on the other hand, salt production do not appear in the urban collective image, which leads to a study of protection of the memory of the cultural landscape.

*Professora Dra. Maria do Carmo L. Bezerra, PPGFAU/Universidade de Brasília, investigadora Visitante em ESTAM/DUyOT, Universidad Politécnica de Madrid

\section{INTRODUÇÃO}

A atividade salineira é milenar e possui trajetória tão longa quanto à história da humanidade (DAMASÍO,2009). No Brasil não se tem notícia de sua existência anterior a colonização portuguesa quando são instaladas com os primeiros povoados na costa atlântica nordestina. Os portugueses vindos da península Ibérica eram conhecedores da produção do sal pois, junto com a Espanha, 
faziam parte da maior área produtora de sal do mundo à época, sendo, ainda hoje da Europa.

Assim, possuindo tradição na produção do sal encontram no nordeste brasileiro as condições naturais propícias e instalaram, de forma rudimentar, salinas próximas às cidades na desembocadura de rios para a extração do sal marinho. Esse era utilizado para curtir couros e na salga de carnes e peixes. Entre as primeiras salinas se destacam as de Itamaracá, em Pernambuco, e de Serigi, em Sergipe que remontam o século XVI.

As salinas passaram a fazer parte da paisagem das cidades junto com um conjunto de atividades de subsistência como a agricultura e a pecuária que se mesclavam com as pequenas áreas urbanas. O salineiro, o trabalhador do sal, fazia parte da paisagem dos povoados assim como os enormes tanques brancos em que semeavam. A partir do fim do século XVII essas áreas começam a sentir a concorrência das salinas do Rio de Janeiro que antes eram de produção precária e de condições ambientais inferiores, mas que passaram a ser fomentadas pela família real portuguesa que chega ao Brasil em 1808. Essa se constituiu na primeira etapa de um processo de redução da importância das salinas de muitas cidades nordestinas. No século XIX quando já não mais exportam para a região sudeste sua produção passam a atender apenas ao mercado local. Uma exceção é o Rio Grande do Norte que continuou com produção significativa devido a sua excepcional condição ambiental para a produção. Esse tema é estudado de forma detalhada em e Diniz, 2008

Mas será na década de 1970, com as grandes transformações no perfil demográfico brasileiro, devido às mudanças na base econômica que levaram a uma urbanização acelerada que durara até a década de 1990, que as salinas urbanas passam a não resistir à pressão da demanda por terras para expansão urbana. Detentoras de grandes áreas, próxima ao mar no momento que esse, também, passou a ser ponto de interesse para moradia da nova burguesia urbana, as áreas de salinas são parceladas e são absorvidas pela cidade. Ao mesmo tempo, na década de 1970, no rastro da industrialização, ocorre uma reviravolta na produção salineira ao se estabelecer no Rio Grande do Norte a produção industrial do sal, com um porto de exportação próprio. Fato que concentrará toda a produção nacional levando à ruína as salinas artesanais.

No contexto de declínio da atividade salineira e de expansão das cidades merece discussão as condições de inserção dessas áreas a paisagem cultural e ambiental das cidades nordestinas. A paisagem cultural pode ser entendida como interface da Natureza com a Sociedade, onde por meio das diversas atividades demandadas pela base social o espaço natural é transformado por meio das diversas formas de produzir, habitar, circular e se divertir. A paisagem é, assim, uma noção diagonal, transdisciplinar, que permite a articulação sócio-espacial. (RODRIGUEZ E SILVA, 2002)

Vale destacar que no Brasil desde os anos de 2007 se discute a criação de uma categoria de proteção dedicada à paisagem cultural, mas sem nenhuma norma editada, apesar do entendimento de vários autores de que existe base legal, na própria Constituição Brasileira, para a criação de tal categoria. (SCIFONI, 2016). No contexto internacional, em especial no caso europeu, desde a década de 1990 se iniciaram as discussões sobre a proteção de paisagens 
culturais e, dentre outros documentos, foi assinada a Convenção Europeia da Paisagem em 2000, fato que levou aos países membros da Comunidade Européia a editarem suas legislações próprias. As paisagens salineiras se enquadram nessa categoria e hoje existem muitos estudos e projetos de proteção dessas paisagens. (ROMÁN, 2014)

A princípio vale destacar que predominou um total silêncio em relação ao desaparecimento das salinas artesanais nordestinas, não houve nenhuma ação institucional ou da sociedade quando essa estava em risco. Contribuiu para tal o fato das salinas urbanas do nordeste brasileiro além de não contarem com proteção legal, serem muito rudimentares, sem grandes edificações que mobilizasse o interesse da comunidade local em sua preservação.

Por outro lado, sua atividade produtiva era vista como extremamente degradante para seus trabalhadores. Os salineiros exerciam seu ofício debaixo de sol forte, expostos ao vento, a água salgada e sofriam queimaduras, insolação, cegueira, envelhecimento precoce ou morte prematura. Apesar do desemprego que o declínio das salinas artesanais promoveu a atividade não encontrou defensores. Outro fator que pode ser acrescentado para se entender o contexto de descaso com a ruína da atividade salineira nessas localidades foi 0 estabelecimento da legislação ambiental, no fim dos anos de 1970 e início de 1980. Instaladas em regiões de manguezais, um ecossistema protegido, as salinas eram, e ainda são, vistas como uma atividade impactante do ecossistema.

Diante de todos esses fatores, de lógica econômica, social e ambiental as salinas sucumbiram e hoje é difícil encontrar vestígios dessas áreas nas cidades. Os estudos sobre o tema da paisagem salineira são muito raros, quase inexistentes e às vezes se reportam aos conflitos com a legislação ambiental. Por fim, o que se coloca como tema do estudo é a identificação dessas áreas nas cidades em que existiram salinas e como hoje elas estão ocupadas. O caso que será objeto de estudo se refere às Salinas Diogo na cidade de Fortaleza, estado do Ceará onde a pesquisadora possui memória afetiva dessas áreas do período de sua juventude vivida na cidade, e que hoje se integrou a cidade na forma de um parque urbano.

\section{MÉTODO DE ANÁLISE E MATERIAIS}

O estudo se fundamenta nos conceitos de proteção de paisagem cultural e natural para discutir promoção de qualidade de vida nas cidades. Valeu-se da evolução da base histórica da atividade salineira e da expansão urbana na década de 1970 no Brasil para entender a desativação e inserção das áreas salineiras na malha urbana e das condições ambientais para sua reinserção como infraestrutura verde e patrimônio cultural. Considerou os estudos sobre recuperação dos manguezais onde se localizavam as salinas como condição para sua inserção nas áreas urbanas como infraestrutura verde.

Diante dos escassos meios de registro das áreas de salinas e do estágio inicial dos estudos de campo da pesquisa quando não se dispõe de imagens e cartografia georreferenciada das área de salinas artesanais desativadas nas 
cidades nordestinas, o estudo de caso esse se valeu de fotos e imagens históricas para localizar e ilustrar fatos e achados da pesquisa realizada até 0 momento.

\section{CONTEXTO DA PRODUÇÃO DE SAL NO BRASIL}

As salinas brasileiras produzem sal marinho pela evaporação da água do mar ou de lago de água salgada. O sal é obtido através do bombeamento da água do mar para salinas formadas por tanques rasos de evaporação a céu aberto. A evaporação é indispensável para a produção de sal, o que faz com que a costa litorânea do nordeste brasileiro reúna as condições ideais: clima tropical; ventos constantes; índices pluviométricos baixos; temperaturas sempre acima dos $30^{\circ}$ C; área plana para os tanques de evaporação; e, solo naturalmente impermeável.

Até 1631 , a produção e o comércio de sal eram livres no Brasil, também, Portugal enviava sal no lastro de embarcações que vinham em busca de açúcar e outros gêneros de exportação. Nessa época os portugueses decidiram auferir lucro como os únicos vendedores ao mercado brasileiro e, em 4 de agosto de 1631, foi estabelecido por alvará o estanque do sal, que proibia sua produção no Brasil. Na realidade, isso só fez com que a produção local, que ocorria de forma predominante do litoral do nordeste, passasse a ser clandestina, o que a manteve sem incrementos tecnológicos por quase toda sua existência. (Figura 25). As salinas só foram liberadas em 1801, com a vinda da família real portuguesa ao Brasil fugindo dos franceses, que por sua vez, vieram a dominar a indústria de sal portuguesa.
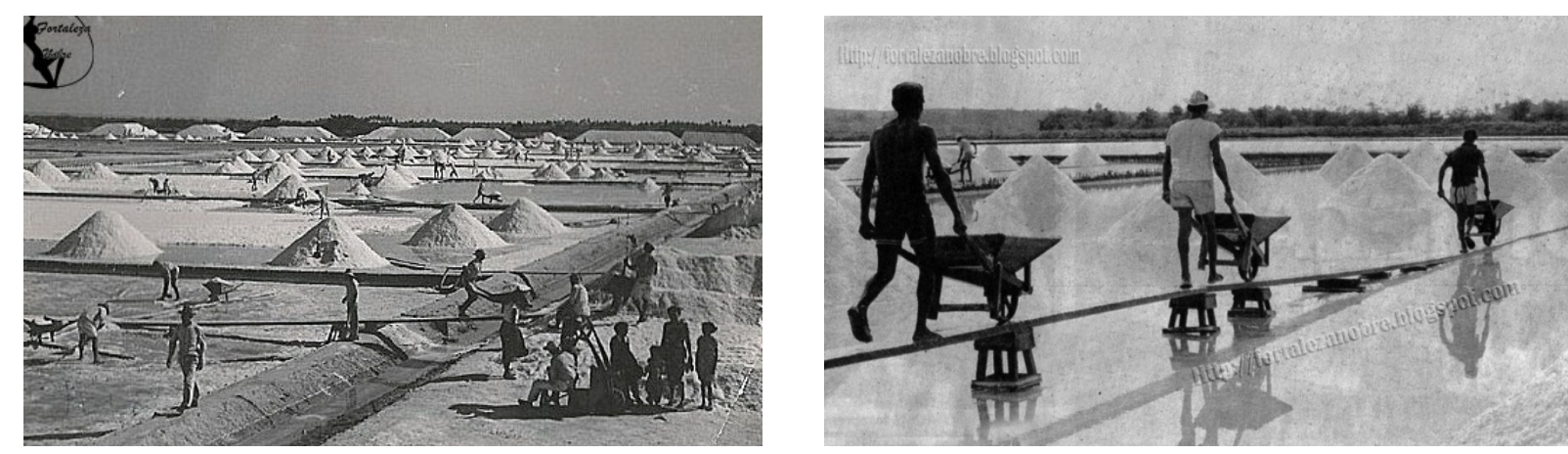

Figura 25 - Sal produzido no sistema artesanal em antigas salinas no Nordeste Fonte: https://br.pinterest.com/pin/702702348082144581/?lp=true (arquivo Nirez)

Dentro desse novo contexto, no fim do século XVIII, instalados no Rio de Janeiro os portugueses passaram a incentivar a indústria do sal no litoral do Estado onde já existia uma produção no entorno da Lagoa de Araruama, uma laguna de alta salinidade. Em 1797 haviam 9 salinas na região e a partir de 1808, com técnicas trazidas pelos portugueses de Figueira da Foz e Aveiro, a Região dos Lagos, entre Cabo Frio e Saquarema passou a ser a maior produtora nacional por um período não muito grande devido sua proximidade com grandes centros urbanos. A região se consolida com o crescimento do mercado 
consumidor na região sudeste do Brasil (Rio de Janeiro e São Paulo), e em 1930, a região entre Cabo Frio, São Pedro da Aldeia e Araruama possuía cerca de 120 salinas.

Até o início dos anos de 1940 e 1950 o estado do Rio de Janeiro continuava sendo um dos maiores produtores de sal do país, enquanto as salinas nordestinas ficaram com produção para subsistência local, com exceção do Rio

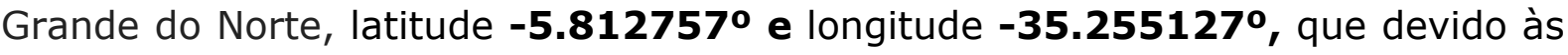
condições geográficas muito superiores, continuava competitivo mesmo estando deslocados dos centros produtores. (Figura 26).

\begin{tabular}{l|l|l|l|l}
\hline PRODUÇÃO DE SAL MARINHO NO BRASIL & $\mathbf{2 0 1 3}$ \\
\hline \multirow{2}{*}{ ESTADOS } & $\mathbf{1 9 3 8}$ & Percentual (\%) & Toneladas (t) & Percentual (\%) \\
\cline { 2 - 5 } & Toneladas (t) & --- & --- & --- \\
\hline PA & --- & 2,40 & --- & --- \\
\hline MA & 18.145 & 0,66 & 8.000 & 0,1 \\
\hline PI & 5.000 & 5,66 & 108.000 & 1,5 \\
\hline CE & 42.756 & 72,79 & 5.589 .000 & 94,5 \\
\hline RN & 549.494 & 0,40 & --- & --- \\
\hline PB & 3.057 & 0,63 & --- & --- \\
\hline PE & 4.757 & 0,14 & --- & --- \\
\hline AL & 1.086 & 5,06 & --- & ---- \\
\hline SE & 38.263 & 1,25 & --- & --- \\
\hline BA & 9.458 & 0,01 & --- & --- \\
\hline ES & 62 & 10,96 & 206.000 & 2,9 \\
\hline RJ & 82.793 & 100 & \multicolumn{2}{l}{} \\
\hline BRASIL & 754.871 & & \multicolumn{2}{l}{} \\
\hline
\end{tabular}

Figura 26 - Produção brasileira de sal marinho em toneladas e percentual por Unidade da Federação nos anos 1938 e 2013.

Fonte: Anuário Estatístico do Brasil - 1953 e Sumário Mineral Brasileiro ano de 2014. (Diniz, Vasconcelos, Martins, 2015)

O Estado do Rio Grande do Norte possui grandes áreas de planícies flúviomarinhas em especial nos Rios Mossoró e Açú, chegando, em alguns trechos, a passar dos 10 quilômetros de largura (Figura 27). Essas áreas possibilitaram a mecanização da produção com evaporadores e cristalizadores com áreas superiores aos dois quilômetros quadrados, por onde podem transitar colhedeiras e onde podem ser instaladas esteiras mecânicas. A mecanização no Rio Grande do Norte se iniciou na década de 1960 e veio a alterar não só a capacidade produtiva nacional, mas também desconstruiu as salinas artesanais em todo o país.
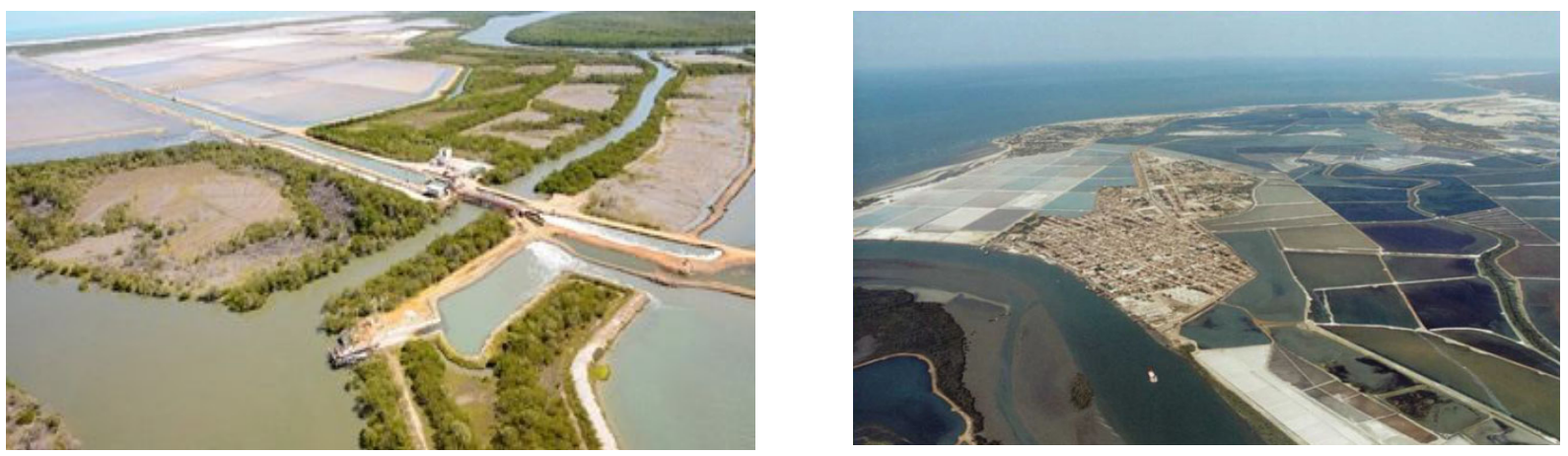

Figura 17 - Os ecossistemas de manguezais e lagoas favorecem a instalação de salinas Fonte: Salinas no estuário do rio Apodi no Rio Grande do Norte, Costa et alli, 2013 
Hoje, $90 \%$ da produção do sal marinho estão localizadas nas salinas do litoral norte do Estado do Rio Grande do Norte, denominado terra do sal. Os municípios onde a produção está concentrada são os de Galinhos, Macau, Grossos, Porto do Mangue, Guamaré e Areia Branca - região conhecida com o nome de Costa Branca. Na cidade de Areia Branca, que possui hoje 30 mil habitantes, está localizado o Porto-Ilha de Areia Branca, (ilha artificial) principal terminal de distribuição do sal para demanda no mercado interno brasileiro. (Figura 28).
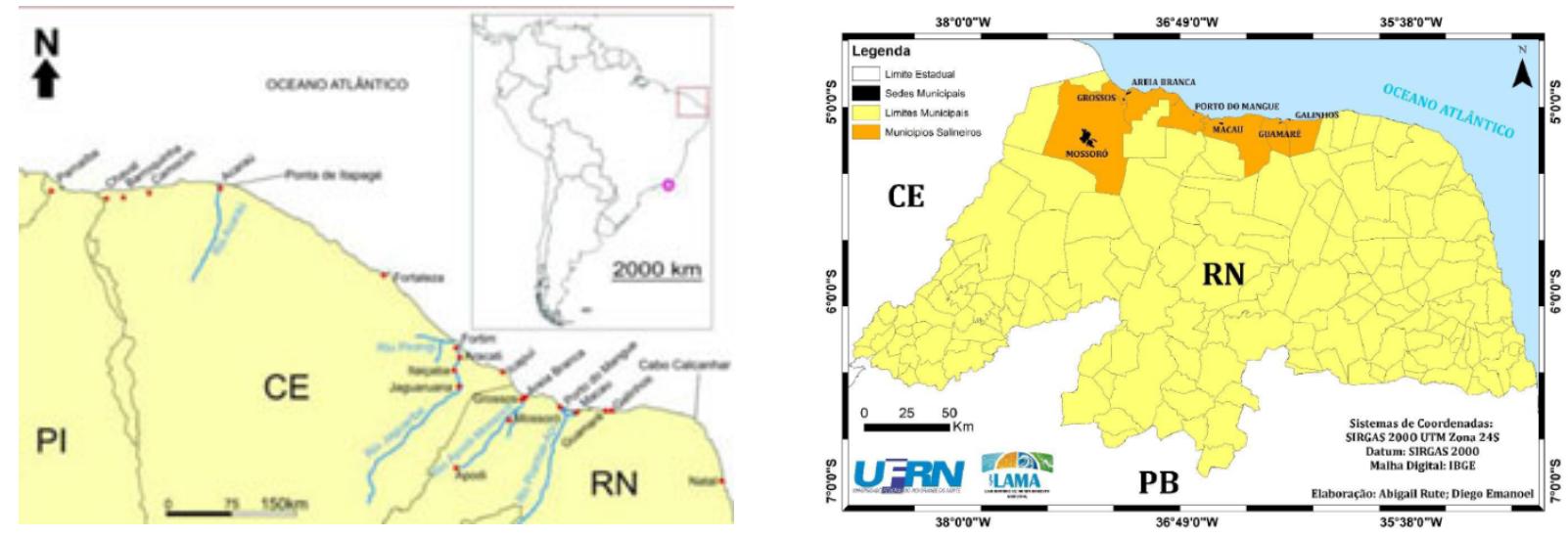

Figura 28 - Localização das Salinas no Nordeste Brasileiro, Ceará e Rio Grande do Norte (esq.) e Municípios produtores de sal no Rio Grande do Norte (dir.)

Fonte: Montagem da autora a partir de mapa do Brasil (esq.) e Silva, Rute e Silva D. E. M. 2015 in Silva, 2015 (dir.)

O Porto-Ilha de Areia Branca foi construído em 1974 e passou a transformar as condições da região onde está localizado, com influência em todas as cidades onde se produzia sal no nordeste brasileiro e no litoral do estado do Rio de Janeiro que desde o Brasil Colônia no início do século XVII tinha uma produção significativa. (Figura 29).

O Brasil por sua vez passou a terceiro produtor de sal marinho no mundo sendo o primeiro os EUA, com produção de 41 milhões de toneladas/ano, seguindo da China com 31 milhões toneladas/ano, e o Brasil com 7 milhões toneladas/ano, das quais $90 \%$ no estado do Rio Grande do Norte e $10 \%$ região dos Lagos no estado do Rio de Janeiro.
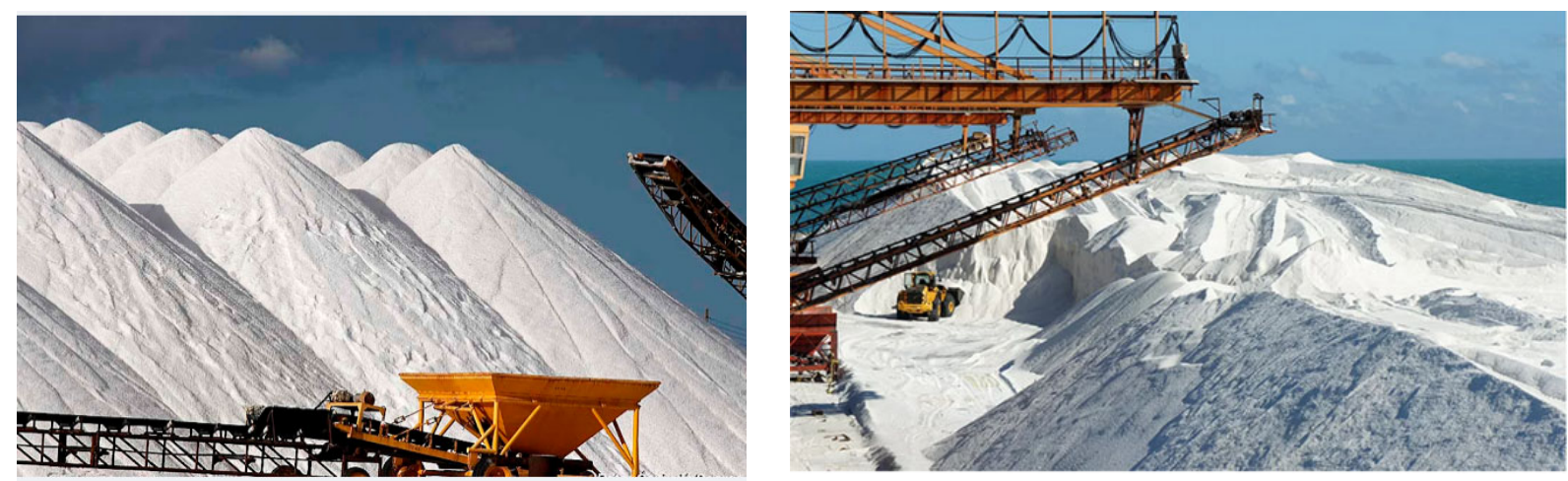

Figura 29 - Armazenagem do sal produzido em sistema industrial no Rio Grande do Norte Fonte: http://www.bloglucianoseixas.com/2019/01/mpf-quer-retirada-de-salinas-de-areas.html (Foto: Canindé Soares) 


\section{AS SALINAS: CONTROVÉRSIAS ENTRE PAISAGEM CULTURAL E NATURAL}

As salinas de sal marinho se instalaram em planícies flúvio-marinhas em ecossistemas de manguezais ${ }^{26}$ que são protegidos por legislação ambiental, e hoje, se encontram muito reduzidos em relação à proporção espacial que já ocuparam. Essa alteração não se deve apenas às salinas, mas também, à ocupação urbana, a criação de camarões e outras atividades que se realizam próximo à costa em zonas de estuários. (BARROS; SANTOS, 2010).

No passado não existiam restrições ambientais e, a partir dos anos de 1980, quando a base da legislação ambiental brasileira foi estabelecida a produção já estava toda concentrada no Rio Grande do Norte, que possui grandes áreas de mangue ${ }^{27}$, principalmente, os apicuns (ecossistemas de áreas alagadiças). As salinas chegam a ocupar 19 milhões de metros quadrados desse ecossistema com uma produção de 80 mil toneladas de sal (Figura 30).
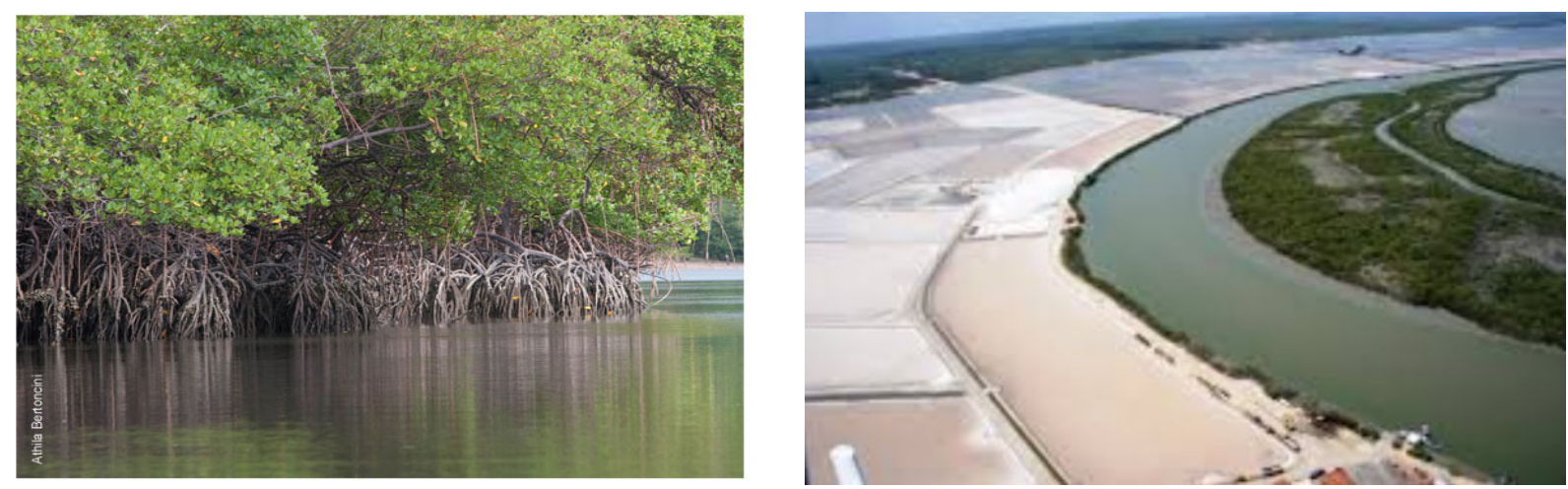

Figura 30 - Ecossistema de mangue preservado (esq.) e Ecossistema ocupado por salinas (dir.) Fonte: Athila Betoncini in site do ministério do meio ambiente do Brasil

https://www.mma.gov.br/biodiversidade/biodiversidade-aquatica/zona-costeira-e-marinha/manguezais.html acessado em dez 2019 (esq.) e O Eco, 2019 . https://www.oeco.org.br/noticias/bolsonaro-autoriza-exploracao-salineira-em-app-no-rio-grandedo-norte/ (dir.)

O tema da convivência entre atividade salineira e o manguezal tem sido objeto de conflito com a proteção das APP - Áreas de Preservação Permanente, faixas a margem dos rios no Brasil. (Figura 30). Na revisão do Código Florestal (Lei $\mathrm{n}^{\circ} 12.651$ de 2012) os manguezais comparecem com o status de APP em toda sua extensão. O assunto é controverso porque existem atividades, dentre elas a produção de sal marinho, que só ocorrem nessas áreas. Estudo sobre a sustentabilidade e a valoração do ecossistema de manguezal tem sido

\footnotetext{
${ }^{26}$ Os manguezais são ecossistemas costeiros que se originaram nas regiões dos oceanos Índico e Pacífico e que distribuíram suas espécies pelo mundo com auxílio das correntes marinhas durante o processo da separação dos continentes (HERZ, 1987). Estes ambientes estão presentes nas faixas tropical e subtropical do planeta, ocupando regiões tipicamente inundadas pela maré, tais como: estuários, lagoas costeiras, baías e deltas. Estas regiões caracterizam, mas não obrigatoriamente, misturas de águas dulcícolas e oceânicas.

27 Segundo a Resolução do Conselho Nacional do Meio Ambiente - CONAMA n 303 DE 2002 no seu art. 30, IX, as restingas são APP em faixa mínima de trezentos metros, medidos a partir da linha de preamar máxima, e em qualquer localização ou extensão, quando recoberta por vegetação com função fixadora de dunas ou estabilizadora de mangues, sendo as dunas também consideradas APP.
} 
desenvolvido para avaliar a permanência da atividade salineira. (FERNANDES, 2019).

Em outra abordagem sobre as alterações da paisagem em decorrência da atividade salineira se coloca o destino das áreas onde a atividade declinou. Em paralelo aos impactos econômicos para as populações que viviam dessa atividade foi deixada para traz áreas de manguezais alterados. Muitas dessas, próximas às cidades, resultaram ocupadas por meio aterramento por atividades urbanas as mais diversas em período entre o fim dos 1970 e início dos 1980, quando não vigoravam proteção a esse ecossistema. Outras áreas que não possuíam o atrativo imobiliário se converteram em fazendas de camarão nas décadas de 1980 e 1990, como no caso do Estado do Ceará que é, hoje, o maior produtor de camarão do Brasil.

Por outro lado, as áreas antes dedicadas à produção de sal, e que foram abandonas nas três últimas décadas e não tiveram outra ocupação econômica se encontram, hoje, com seus manguezais bastante recuperados, como na laguna (lagamar) do Iguape, no Município de Aquiraz, no Estado do Ceará e o Parque Estadual do rio Cocó, área inserida dentro da malha urbana de Fortaleza (DINIZ, 2008). A oportunidade que essas áreas significam para que se instalem parques e áreas verdes em cidades que, em sua maioria, não dispõem de uma estrutura urbana com essas funções, desponta como um ponto de estudo relevante.

Não ausência de estudos que identifiquem todas das às áreas de salinas que existiam próximas as áreas urbanas nordestinas no período entre os anos de $1960 / 1970$ para que se possa verificar o papel que cada uma veio a ocupar dentro das cidades, bem como as oportunidades urbanas que, ainda, existem para sua reinserção como área de patrocínio cultural e ambiental, aqui será estudado um caso específico com base no conhecimento vivencial do pesquisador. A Salina Antonio Diogo localizada às margens do Rio Cocó na cidade de Fortaleza, Ceará. De qualquer sorte, o estudo mais amplo para conhecer o que aconteceu nas demais áreas e possibilitar uma análise de conjunto se faz necessário.

\section{ANTIGAS SALINAS DIOGO, O ATUAL PARQUE DO RIO COCÓ: QUANTOS SABEM SE TRATAR DA MESMA ÁREA?}

Em Fortaleza, cidade hoje com 2,6 milhões de habitantes, nos anos de 1960/1970 contava com cerca de 600 mil habitantes e no seu entorno urbano se localizavam salinas artesanais nas margens do rio Cocó, que possuí influência dos mares ao longo de vários quilômetros devido a topografia extremamente plana. Nas margens do rio predominava uma ocupação por sítios de baixa densidade que funcionavam como áreas de recreio familiar, sem atividade econômica além da subsistência de caseiros. Um desses sítios, o sítio Diogo, explorava sal em longa extensão do rio que ia dos trilhos da ferrovia, onde terminava a zona urbana consolidada, até a desembocadura do rio próximo ao mar. (Figuras 31 e 32). 


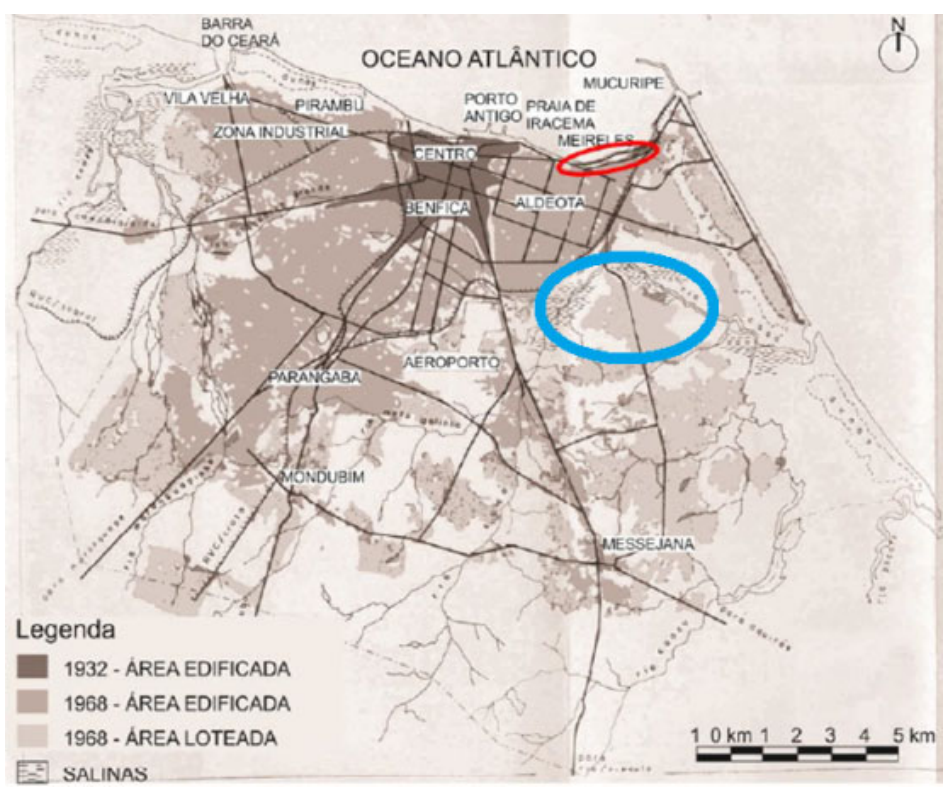

\section{LEGENDA}

Localização do sitio Diogo onde se produzia sal (área fora da zona urbana nos anos de 1960 .

Região de praia onde iniciou a expansão da cidade nos anos de 1960 .

Figura 31 - Localização das salinas artesanais na década de 1960.

Fonte: Accioly,2008
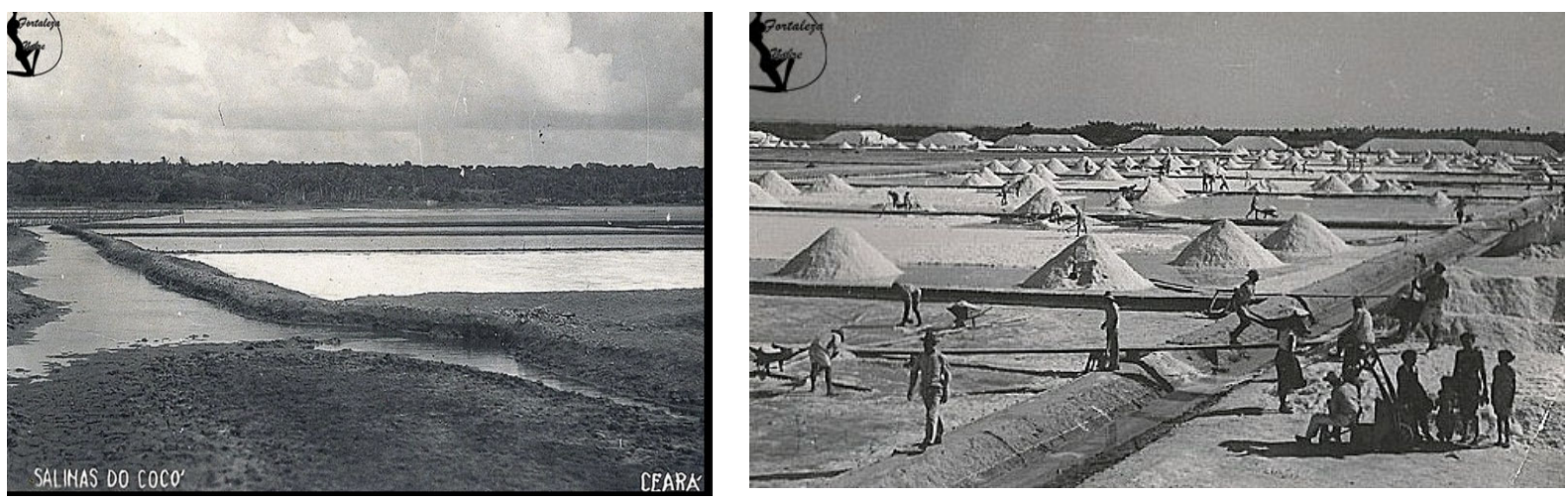

Figura 32 - Áreas das Salinas no Rio Cocó em Fortaleza - CE.

Fonte: http://www.fortalezaemfotos.com.br/2013/02/da-salina-diogo-ao-parque-do-Cocó.html (arquivo Nirez)

Com a forte urbanização dos anos de 1970, Fortaleza ultrapassa o trilho da ferrovia em sentido lesta com a continuidade da Avenida Santos Dumont. A zona leste possuía alguns empecilhos físicos a sua ocupação, os trilhos, as dunas e o rio coco e suas largas margens de inundação e manguezais. A avenida Santos Dumont sobe as dunas e vai até o mar de leste da cidade, e aos poucos são estabelecidas vias transversais que abrem caminho para as áreas de sudeste que ultrapassam o rio Cocó. Uma delas é a avenida Washington Soares que possui uma ponte sobre o rio Cocó (Figura 33). 


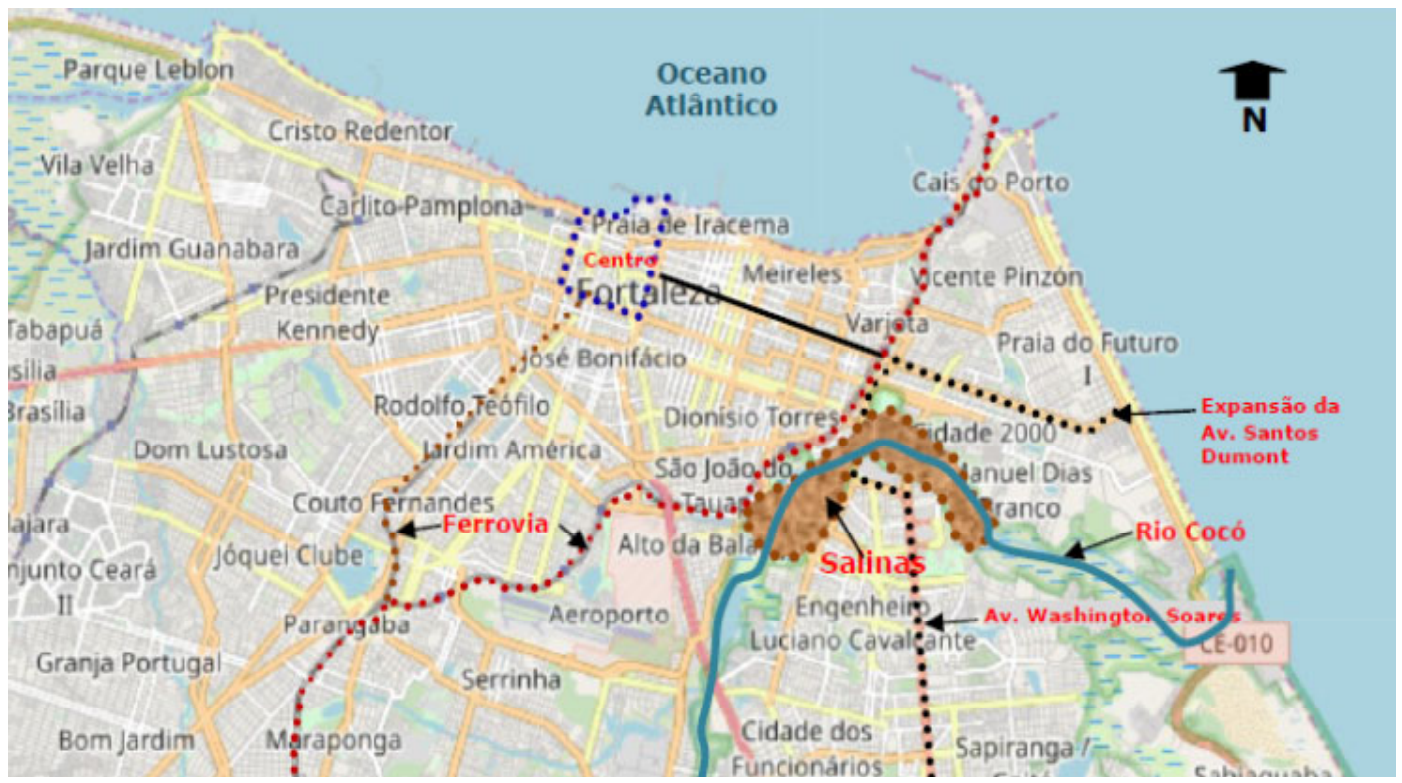

Figura 33 - Imagem atual com expansão urbana na área das Salinas na década de 1970. Fonte: Prefeitura de Fortaleza in https://www.cidade-brasil.com.br/mapa-fortaleza.html, adaptado pela autora 2019.

A ocupação sudoeste possui como marco a instalação da UNIFORUniversidade de Fortaleza, a primeira Universidade privada do Estado, e mais tarde com o Shopping Iguatemi, esse próximo a ponte e ao rio dentro de uma área da antiga salina Diogo. (Figura 34)

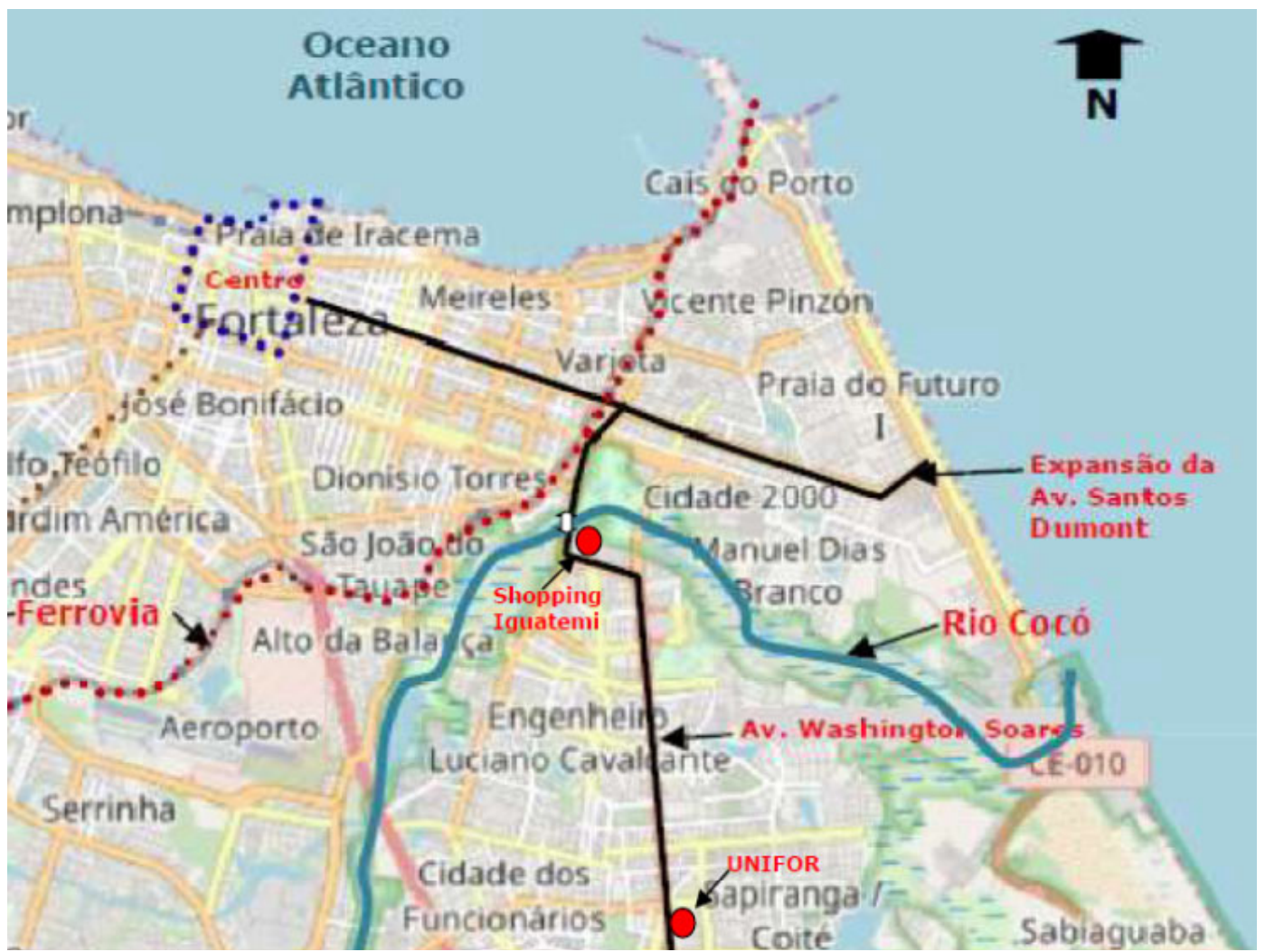

Figura 34 - Salinas desativadas e expansão sudoeste em consolidação

Fonte: Prefeitura de Fortaleza in https://www.cidade-brasil.com.br/mapa-fortaleza.html, adaptado pela autora 2019. 
Quando a área desponta como um possível vetor de expansão urbana as salinas Diogo passavam por momentos difíceis devido à crescente concorrência da industrialização do sal no Rio Grande do Norte e logo fecha suas atividades com seu dono vendendo as terras mais próximas do sistema viário e que sofriam menores influencia das inundações. Uma delas foi vendida para a implantação do Shopping, iniciado no fim dos anos de 1970 e inaugurado em 1982. (Figura 35).
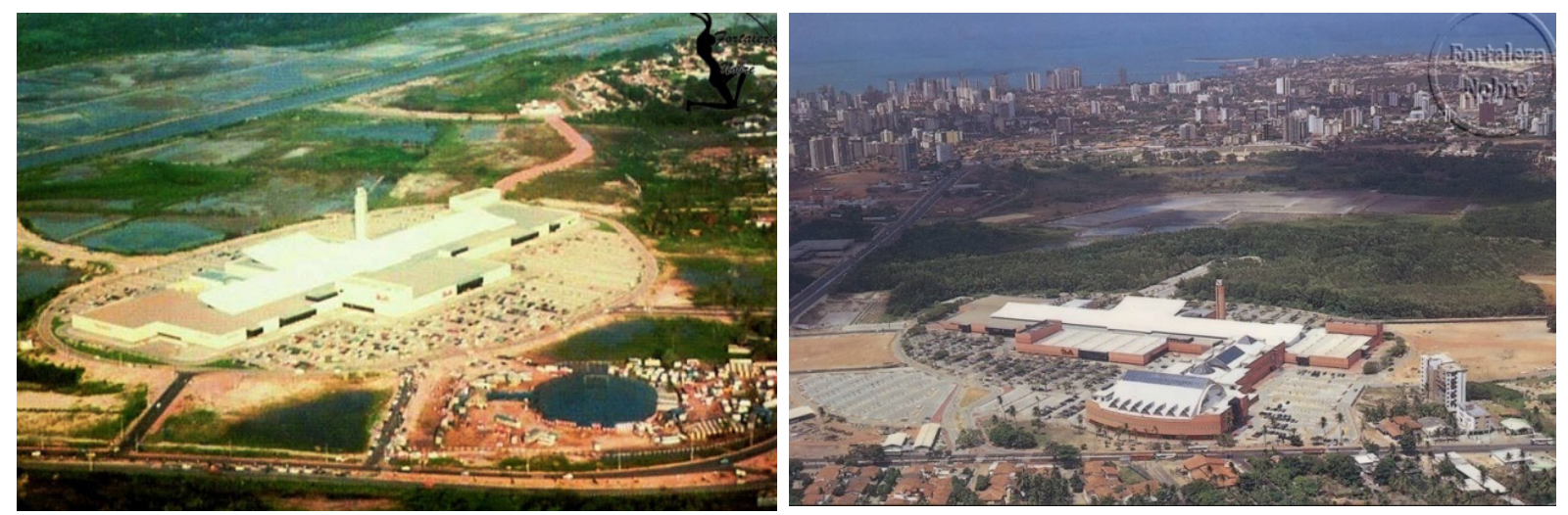

Figura 35 - Início da construção do Shopping na área das salinas (esq.) e Shopping já instalado com mangue das antigas salinas em início de recuperação ao fundo (dir.).

Fonte:http://www.fortalezaemfotos.com.br/2019/da-salina-diogo-ao-parque-do-Cocó.html http://www.naturezabela.com.br/2019/parque-ecologico-do-rio-Cocó-fortaleza.html

As áreas mais próximas as margens do rio que de imediato não interessavam a urbanização e que já contavam com legislação ambiental de proteção ao mangue começa a se regenerar depois de cessada a atividade salineira. A comunidade há mais tempo residente nas proximidades, na zona urbana consolidada, e também, a que se instalava nos novos bairros à sudoeste começam a demandar que as áreas próximas ao rio sejam estabelecidas como parque urbano pela municipalidade. Essa população é composta marcadamente por população de renda média e alta e seu movimento de reivindicação para criar um parque ganha força nos meios de comunicação. O movimento que se inicia em 1977 e chega a êxito com a demarcação oficial e desapropriação das áreas em 2017 quando se cria o Parque estadual do rio Cocó. (Figura 36 e Figura 37).

\begin{tabular}{|l|l|}
\hline 1977 & $\begin{array}{l}\text { Declaração de utilidade pública para fins de desapropriação de uma área as } \\
\text { margens do rio Cocó (Decreto Municipal 4.852) }\end{array}$ \\
\hline 1980 & Inauguração simbólica do Parque do rio Cocó \\
\hline 1986 & $\begin{array}{l}\text { O vale do rio Cocó foi tornado Área de proteção ambiental (decreto municipal } \\
7.302 \text { ) }\end{array}$ \\
\hline 1989 & $\begin{array}{l}\text { Ampliada área de interesse social para fins de desapropriação: entre a BR-116 e } \\
\text { a Avenida Sebastião de Abreu (decreto Estadual 20.253) }\end{array}$ \\
\hline 1993 & $\begin{array}{l}\text { Ampliada área de interesse público social da Avenida Sebastião de Abreu a foz do } \\
\text { rio Cocó ( decreto 22.587) }\end{array}$ \\
\hline 2017 & $\begin{array}{l}\text { Assinado decreto de regulamentação do Parque do Rio Cocó com definição de } \\
\text { seus limites ( decreto estadual 32 248) }\end{array}$ \\
\hline
\end{tabular}

Figura 36 - Cronologia do processo de criação do Parque do rio Cocó. 


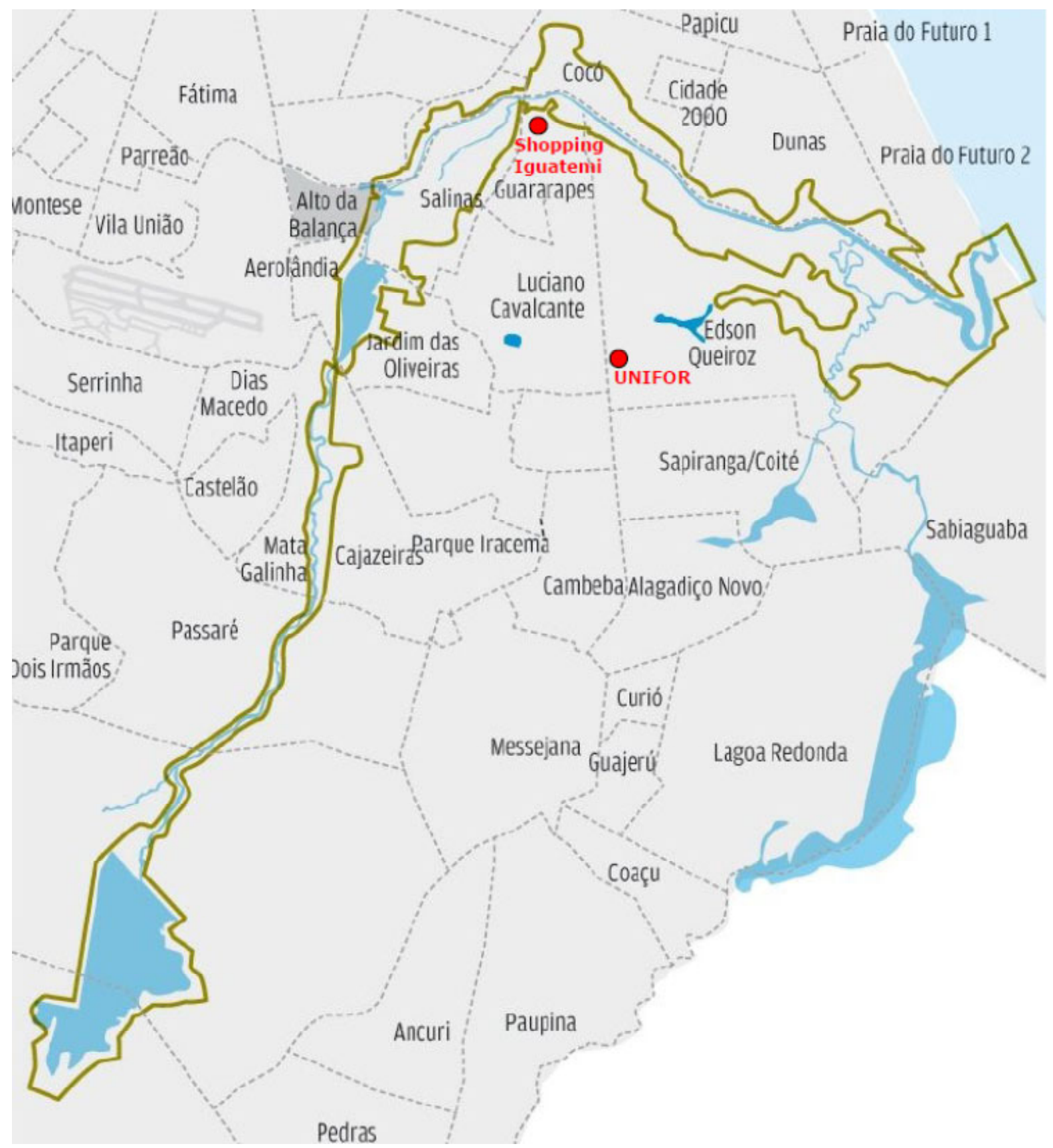

Figura 37 - Delimitação do Parque Estadual do rio Cocó. Fonte: Jornal O Povo de 02/06/2017, adaptado pela autora em 2019.

Hoje, quem passa diariamente pela ponte do rio Cocó na Avenida Washington Soares e visualiza uma grande massa de verde não imagina que a paisagem ali já foi muito diferente. Em tempos atrás, muito bela, também, mas marcada pelo branco das salinas e depois por anos como espaço degradado pelo abandono. A atividade salineira que possui sua integração as características ecossistêmicas e, portanto, possibilitou a recuperação do manguezal após cessar sua produção foi determinante para resguardar a área verde que hoje faz parte da cidade.

O regate ambiental da área é evidente, mas não sua memorial cultural. 0 parque conta com muitas atividades de recreação e com um projeto de 
urbanização de seu perímetro, mas não existem referências as áreas de salinas que constituem sua memória histórica. Desses tempos restou o nome do bairro, Salinas. (Figura 38).
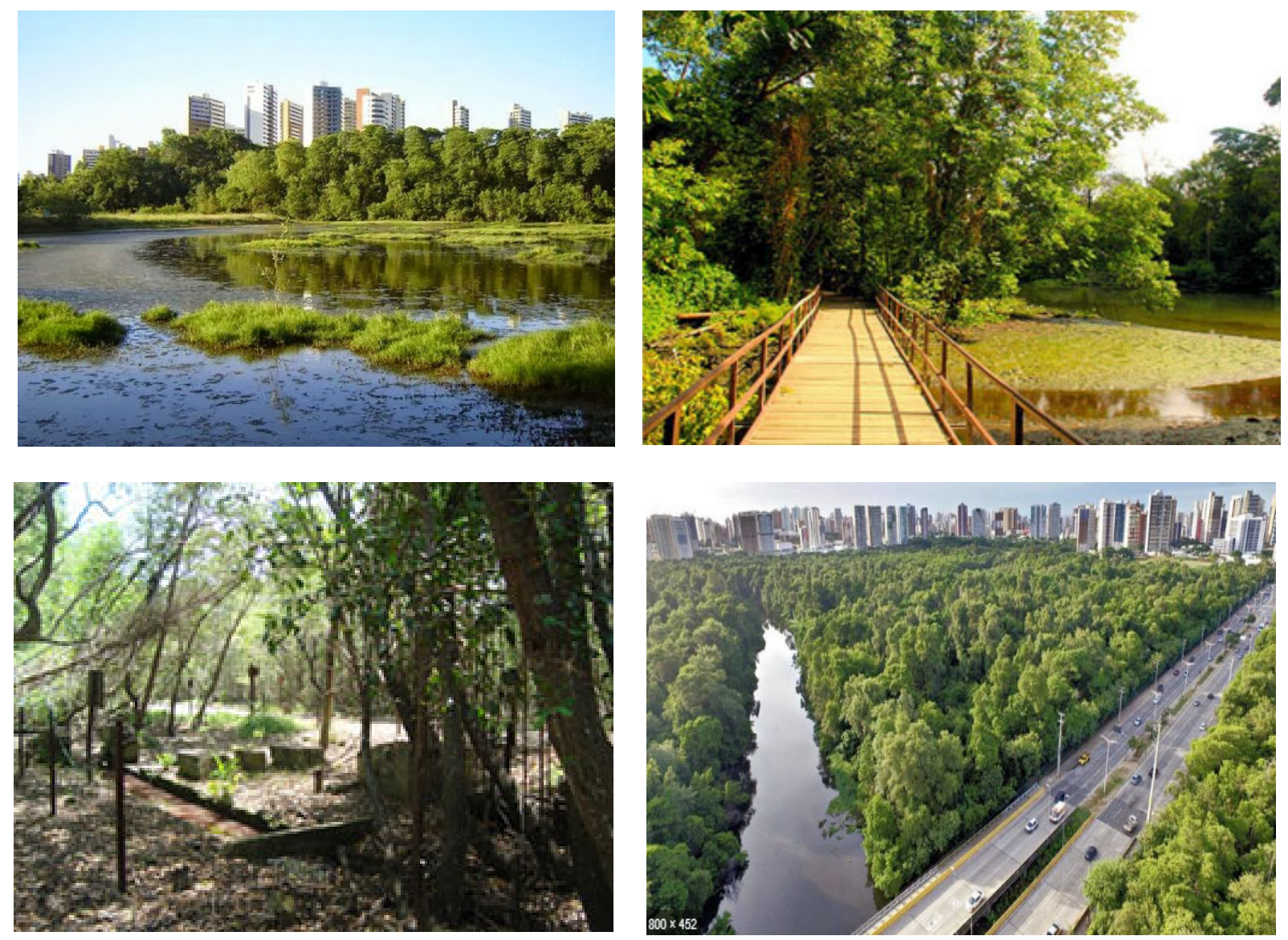

Figura 2 - imagens do Parque Estadual do rio Cocó com detalhe de antigas instalações de salinas. Fonte: http://www.naturezabela.com.br/2019/parque-ecologico-do-rio-Cocó-fortaleza.html

\section{CONSIDERAÇÕES FINAIS}

As áreas de salinas próximas as áreas urbanas e que foram desativadas constituem grande oportunidade de implantação de áreas verdes urbanas, dada a capacidade de recuperação dos ecossistemas de manguezais. A atividade salineira é uma atividade de baixo impacto, uma vez cessada a produção a tendência é a atuo regeneração das áreas.

No caso nordestino, apesar da maioria das salinas terem sido desativadas ao longo dos anos de 1970 e 1980, ainda, existem áreas que se encontram subutilizadas ou marginalizadas dentro da cidade inclusive no próprio rio Cocó em Fortaleza. A relação que essas áreas possuem com os canais hídricos faz com que sejam naturais corredores verdes que podem conectar varias áreas da cidade com atividades ecológicas e culturais. Como é o exemplo da parte preservada do atual Parque Estadual do rio Cocó em Fortaleza.

Sobre o caso relatado, deve-se dizer que se trata de uma exceção, tendo sido mais comum a invasão dessas áreas por assentamentos irregulares com perdas 
ambientais e socioculturais. Do ponto de vista ecológico é relevante a recuperação de parte do ecossistema de manguezais que nas áreas urbanas é quase inexistente. No que se refere à paisagem cultural o resgate da memória da antiga atividade salineira se impõe como parte da cultura do lugar e do papel que o sal desempenhou na historia dos antigos povoados desde a época da colonização.

O êxito da criação do Parque Estadual do rio Cocó se deve ao fato de parte do rio cortar uma zona nobre da cidade e, portanto, ser objeto de pressão da população local para criação de um parque que faz parte de suas demandas urbanas. No sentido de que iniciativas dessa natureza não fiquem ao reboque do acaso e que venham a ocorrer de formas institucionais e integradas ao planejamento urbano deve haver estudo que reconheça sua vocação de inserção à cidade como um elemento de infraestrutura verde e resgate da paisagem natural e cultural das antigas salinas e da cidade. Esses estudos subsidiariam ações mais assertivas de planejamento urbano local.

\section{BIBLIOGRAFIA CONSULTADA}

ACCIOLY, Vera Mamede, Planejamento, Planos Diretores e ExpansãoUrbana em Fortaleza 1960-1992, Tese de Doutorado, Universidade Federal da Bahia, Salvador, 2008.

BARROS, L. F. F.; SANTOS. Aplicação de Técnicas de Geoprocessamento para fins de Análise da Expansão da Salinocultura / Carcinocultura no Estuário de Rio Piranhas - Açu/RN, no Período de 1989 a 2009. In: Reunião Anual da Sociedade Brasileira para o Progresso da Ciência, 62, 2010, Natal. Livro eletrônico Anais São Paulo: SBPC, 2010. Disponível em: <http: // www.sbpcnet.org.br/ livro/ 62ra/ resumos/ resumos/ 1940.htm>. Acesso em: 10 de dezembro 2019.

CÂMARA Ana S. V. M. et alli. Relatório Técnico: a Delimitação do Parque Estadual do rio Cocó: Conflito Socioambiental Decorrente de Sobreposição com APA da Sabiaguaba, Fortaleza, 2016.

COSTA, D. F. S,SILVA A. A. MEDEIROS, D. H. M. LUCENA FILHO M.A, MEDEOROS ROCHA R. LILLEBO A. I. SOARE A. M. breve revisão sobre a evolução histórica da atividade salineira no estiado do Rio Grande do Norte. Brasil - Sociedade \& Natureza. UFU on line (v. 25 p.24/34 2013)

DAMASIO M.F V R, Desenvolvimento da civilização e colonização do Brasil: importância antropológica e cultural da salga como método natural de desidratação da carne, dissertação de mestrado gastronomia e segurança alimentar III, Cento de Excelência em Turismo, Universidade de Brasília, 2009.

DINIZ M., Vasconcelos F. P., M. B. Martins, Inovação tecnológica na produção brasileira de sal marinho e as alterações sócio-territoriais dela decorrentes: uma análise sob a ótica da Teoria do Empreendedorismo de Schumpeter in Sociedade \& Natureza, vol. 27., Set/Dez, 2015. 
DINIZ, M. T. M. Bases para um plano de gestão integrada de zonas costeiras em Jacaúna - Aquiraz -C. Fortaleza, 2008. 137f. Dissertação de Mestrado. Programa de Pós-graduação em Geografia, Universidade Estadual do Ceará - UECE, Fortaleza, 2008. [Links].

FERNANDES, R.T.V. Salinas e Manguezais: Razões do Conflito e Caminhos para Conciliação, Workshop, 2019 in https: //nit.ufersa.edu.br/ wp-content/ uploads/ sites/ 81/2019/03/WORKSHOP_FINAL_08_03_2019.pdf.

RODRIGUEZ, M. M \& Silva, E. V. A Classificação das Paisagens a partir de uma Visão Geossistêmica, Mercator - Revista de Geografia da UFC, ano 01, número 01, 2002.

ROMÁN López, María Emilia, Paisajes de la sal en Andalucía, tese de doutorado na Escola Técnica Superior .de Arquitetura de Madri, Universidade Politécnica de Madri, 2014

SCIFONI, Simone. Paisagem cultural. In: GRIECO, Bettina; TEIXEIRA, Luciano; THOMPSON, Analucia (Orgs.).Dicionário IPHAN de Patrimônio Cultural. 2. ed. rev. ampl. Rio de Janeiro, Brasília: IPHAN/DAF/Copedoc, 2016. (verbete). ISBN 97885-7334-299-4.

SILVA, Rute A. Produçao artesanal do sal marinho no litoral sententrional do Rio Grande do Norte, Universidade Fderal do Rio Grande do Norte, Departamento de Geografia, Monografia de final de curso de Graduaçao, Caioc , 2015 